\title{
Pende Masks in Kauffman Museum
}

\section{JOHN M. JANZEN ・ REINHILD KAUENHOVEN-JANZEN}

$\mathrm{K}^{\mathrm{a}}$ auffman Museum in North Newton, Kansas, has recently obtained a collection of 149 masks of the Pende culture of Zaïre. Over half of these masks constitute a fairly complete repertoire from the Katundu, or central Pende, region in Bandundu province (Figs. 3, 4, 6, 8), while the remaining 68 masks show a cross-section from the eastern Pende region in Kasai province (Figs. 1, 2, 5, 7, 9, 10). The far western zone is not represented. Most of the masks are contemporary, commissioned directly from about a dozen active artists in each area. About fifteen are old, purchased from their owners after several seasons of ceremonial use. Four, commissioned for the collection, were borrowed for ceremonial use.

The collection was made possible by a gift from the senior class of 1969 of Bethel College. For some years, students of

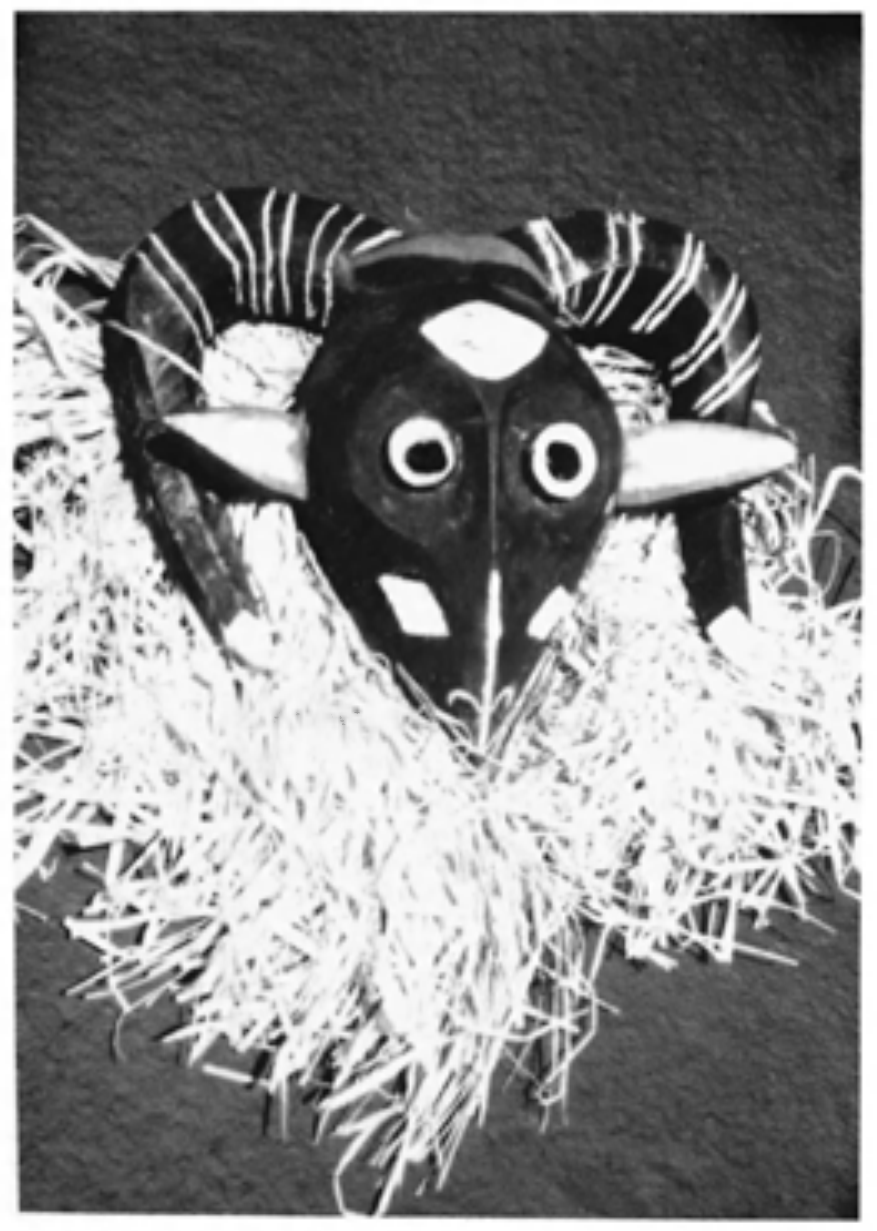

1. KIMEME, THE SHEEP, DANCED IN THE MUKANDA, CARVED BY MUZEMA. KASAI. the College had been participating in "service-study" projects in Zaire and elsewhere under the auspices of the Mennonite Central Committee. Henry Goertz, a student and two-year participant in an extension livestock development project in the general Pende area, carried out the collecting of masks from 1968-70 with the help of several project workers. The Kauffman Museum Committee and others involved in these projects believed it important that the people of central Kansas and the American Midwest learn more directly about the overseas cultures in which they were involved in development and educational work.

A selection of the collection was first exhibited in 1971 in the College's art gallery in a conventional presentation of masks which also included ethnographic texts, photographs and diagrams. Central Kansas audiences, not accustomed to this kind of art, passed it off as merely curious. Thus a different, decidedly didactic approach was developed in the ensuing permanent exhibit in the museum-one that sought to translate the masks' social function in terms of roles and categories in American life.

Collection policy was based on the fact that masks used in Pende society are contemporary rather than just survivors from the past. The Pende value well-made new masks as much as, if not more than, old ones. A good artist can earn a living carving masks commissioned for ceremonies such as the millet dance, a village renewal ceremony following the planting of millet and renewal of hearth fires (Figs. 2, 7 ); the mukanda circumcision camp (Figs. 1, 5, 9); or a chief's inauguration (Fig. 10). But their durability is limited since the soft wood of which they are carved is vulnerable to insects and humidity. Natural pigments with which most masks are painted-mainly river chalk, charcoal, and camwood, mixed with a variety of resins - may be renewed for repeated use. A sponsor of means preparing for a masked ceremony will commission a reputable artist to fashion a mask and its related costumes. The effect of these factors on Pende aesthetic sensibilities is that they are inverse to those of many Occidental art collectors who require an art object to bear a rich patina to be valuable.

The effort to collect masks representative of all known types resulted in an inventory of masks that is larger by far than that of masks apparently used in recent years. On

OPPOSITE PAGE: 2. GIPHOGO, OR MUKISHI WA MUTWE, KASAI, CARVED BY MUZEMA OF MUKUAMA VILLAGE. CALLED "CHIEF OF THE MASKS," IT DANCES IN THE MILLET DANCE (A VILLAGE RENEWAL CEREMONY) AND OTHER CURING CEREMONIES. 3. MUYOMBO, ELDER, IN CLASSIC KATUNDU STYLE OF PENDE MASKS. CARVED BY NGELEKO OF KAMUANI VILLAGE CA. 1963, SEVEN YEARS BEFORE PURCHASE. 4. GITENGA, "EYES," CARVED BY KATULUSHI OF MUNZOMBO VILLAGE, KATUNDU REGION. REPRESENTS POWERFUL TIES TO OTHERWORLD. 5. PANYANGOMBE, KASAI. CARVED BY MUZEMA, IT IS DANCED IN THE MUKANDA, BUT IS ALSO DISPLAYED ABOVE THE DOOR TO LEMBA CHIEFS' RELIC HOUSES. 


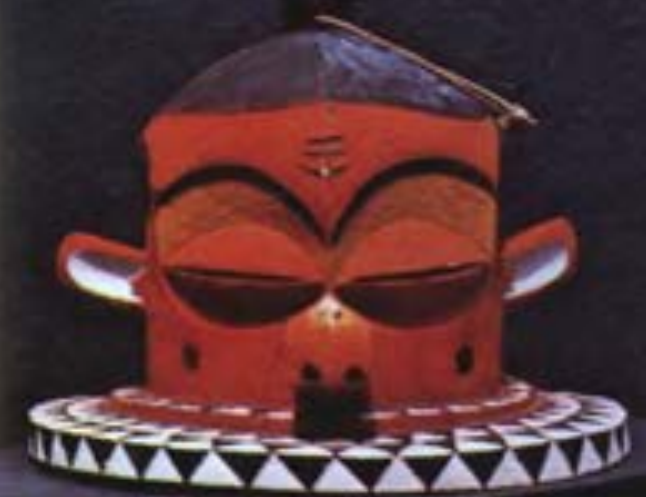

2
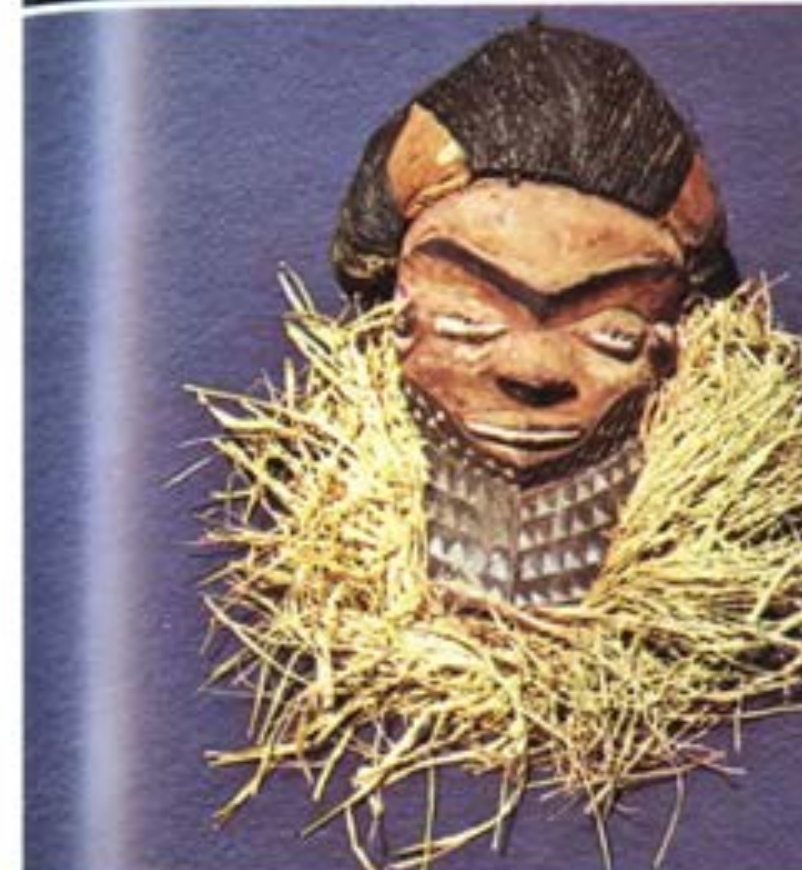

Net

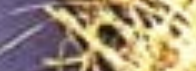

atowe on ars?

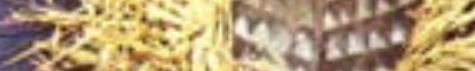

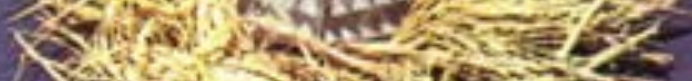

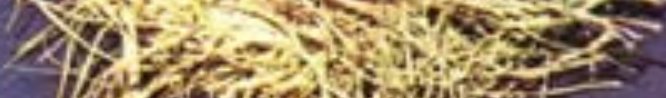

$7 / 7$.
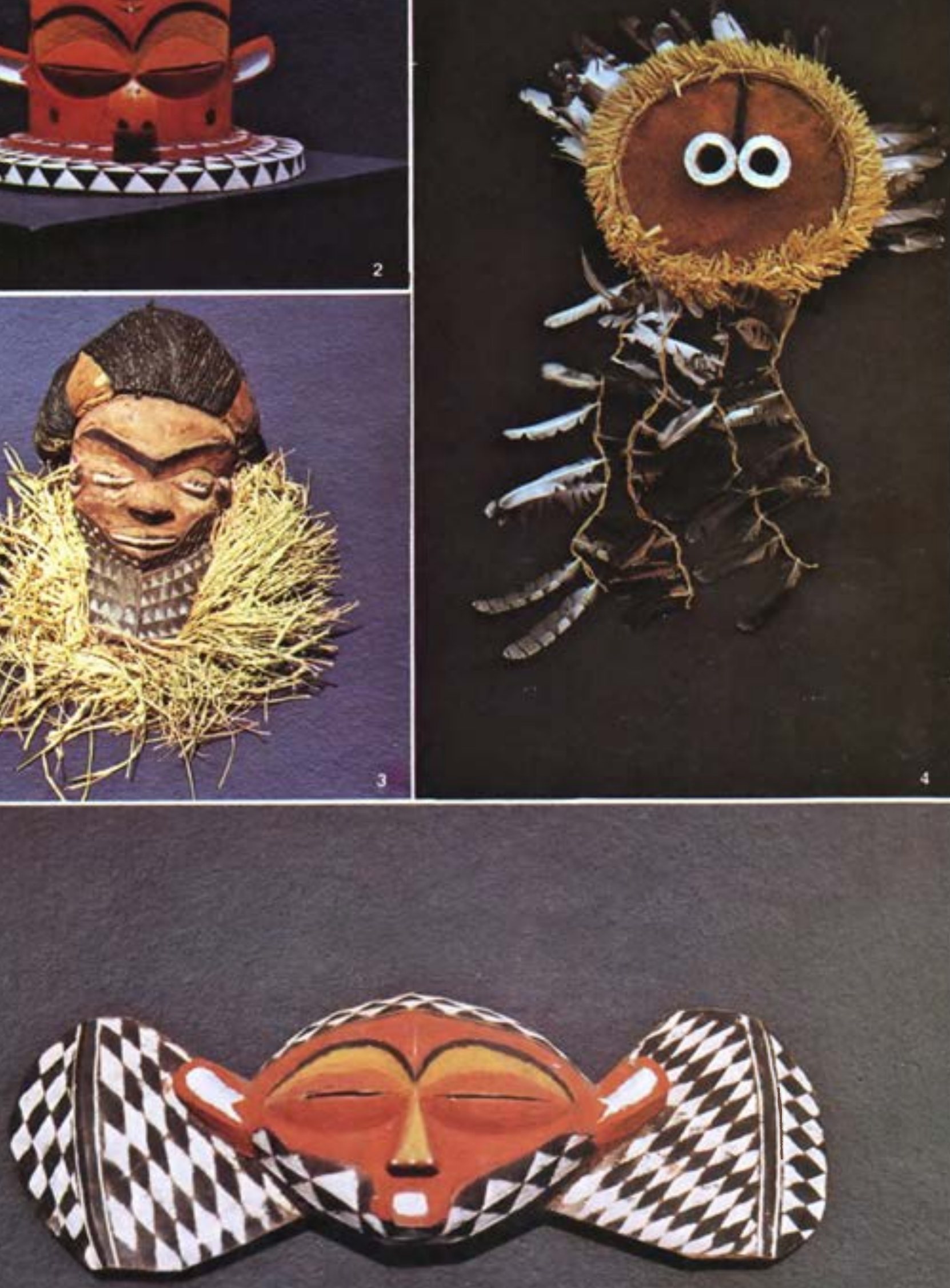


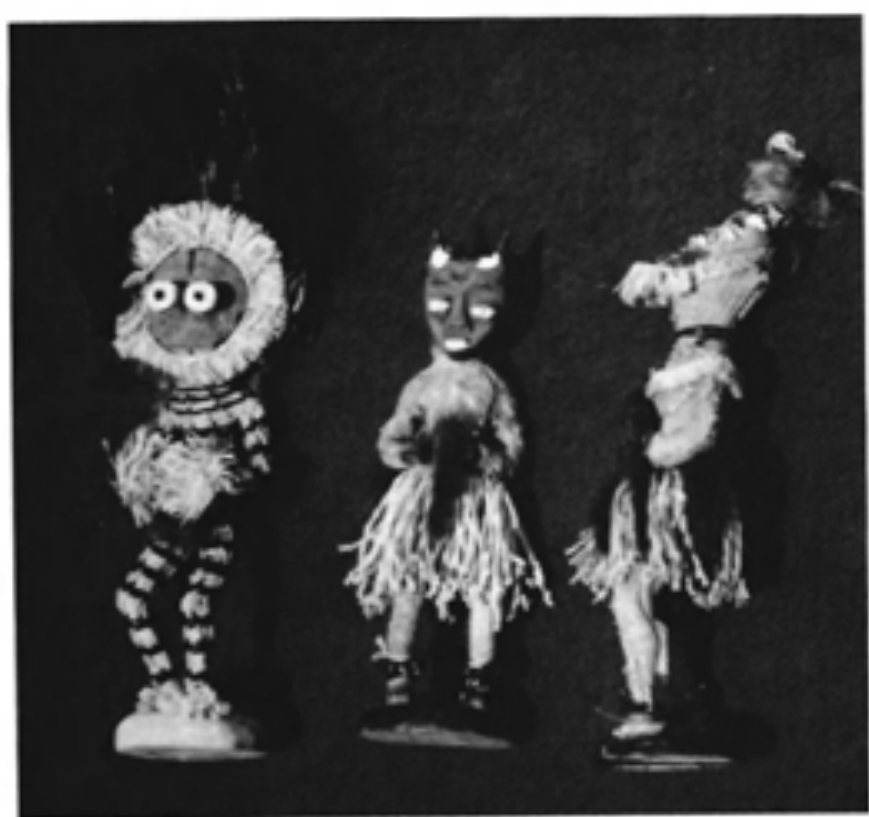

6. MINIATURE "DOLL" MASKED FIGURES, BANDUNDU PROVINCE, OF THE SORT SOLD BOTH LOCALLY AND AT IVORY MARKET IN KINSHASA.

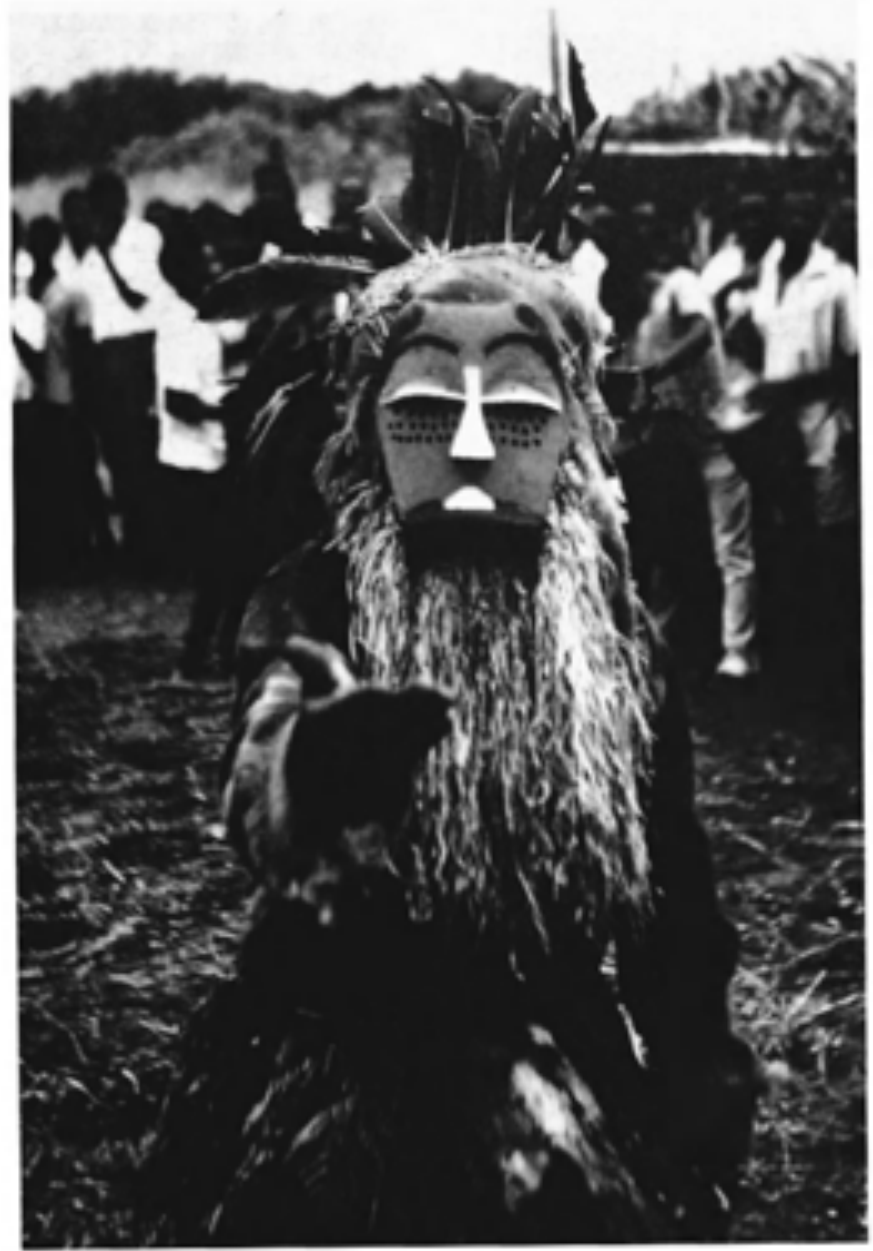

7. KINDOMBOLO, TRICKSTER, DANCES IN MILLET DANCE, NYANGA VILLAGE OF KASAI 1970. THIS MASK, ACQUIRED FOR THE KAUFFMAN MUSEUM COLLECTION, WAS CARVED BY SH'A MANGUANDA OF NYANGA.

8. TUNDU, THE TRICKSTER, KATUNDU REGION OF BANDUNDU PROVINCE. CARVED BY NGELEKO OF KAMUANI VILLAGE AND DANCED IN A VARIETY OF CIRCUMSTANCES. THIS MASK WAS ABOUT FIVE YEARS OLD AT TIME OF COLLECTION. the surface this might suggest a decline of the genre in Pende culture. However, the western Pende were ravaged by the Kwilu part of the 1964-67 civil war, and many of the communities in which collections had been made were displaced during that time, and were only beginning to stabilize again. One mask bears the name of a rebel leader; if it is in fact based on him, it would indicate a renewing and changing genre in which some masks are abandoned while others are invented out of current events.

A basic divergence that became apparent in the inventories from the Bandundu (Kwilu) Pende and the Kasai Pende seems to correlate with their different political structures that antecede recent political upheaval. The Bandundu area is the center of several large chiefdoms while authority in the Kasai Pende is decentralized, vested in a number of parallel chiefly orders, and age-grading is prominent. Hence the masks of the Kasai Pende reflect a more integral role of ritual in the maintenance of public order. while masks of the western Bandundu area mainly serve purposes of entertainment.

In the eastern region the masks are quickly classified by informants into three categories: "masks of the village," "masks of the mukanda initiation," and "masks of power." The first class is used, in whole or in part, in the millet dance and village renewal ceremony held on an irregular though recurring basis as internal social cohesion requires it. The trickster (Fig. 7), the chief, the chief's wife, and the celebrated fertility mask mukishi wa mutwe, or giphogo (Fig. 2 ), enter into this category.

The second category of masks among the eastern Pende pertains to the circumcision camp and initiation to age grades. These masks are entirely animal in character, portraying antelope (Fig. 9), buffalo, domestic animals like sheep (Fig. 1), and other more abstract animal spirits. The

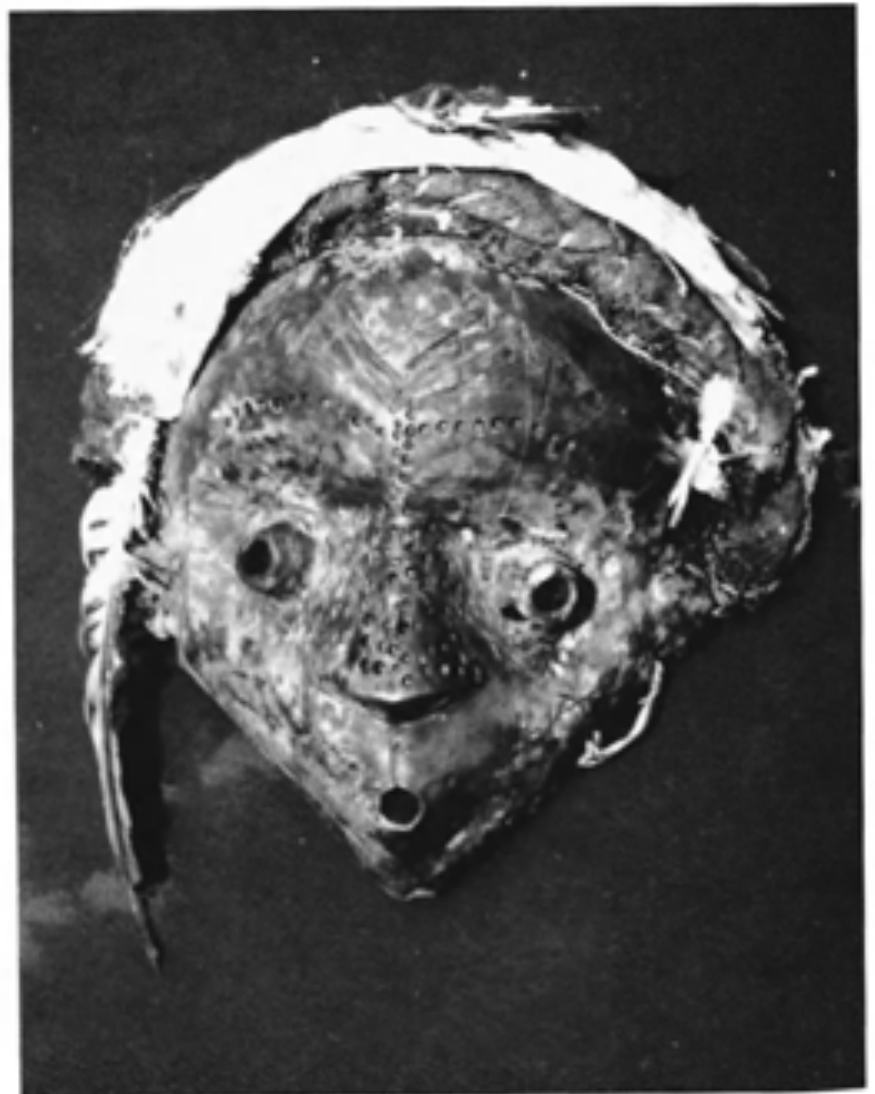




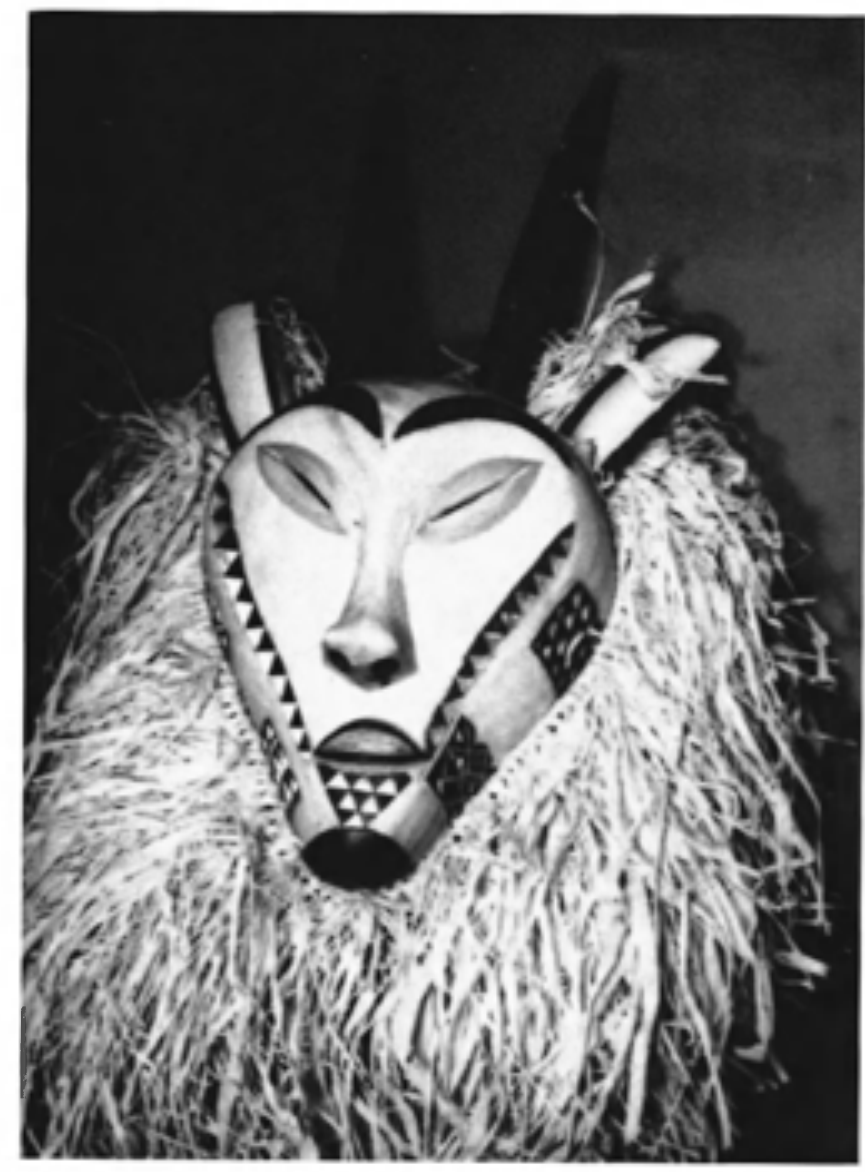

9. MUKHETE (WA ZAMBAJIMBIDI), AN ANTELOPE, KASAI. CARVED BY CHIEF HOLO OF KAYALA VILLAGE, AND DANCED IN THE MUKANDA BOYS' INITIATION.

underlying idea is that the initiates are outside of society during their transition, and are thus "in nature." Indeed, the camps are held in deep bush during dry season when the grass is tall. The third category, exemplified by the mask panyangombe (Fig. 5), is most frequently associated with chiefly symbols of office. The mask is displayed prominently on the insignia houses of chiefs of the various orders. The majority of masks in eastern Pende society are thus subsumed to categories that structure life and thought.

In the western region, far more mask types appear (ca. 60 ), but these are not apparently subsumed to any categories like those noted in the east (ca. 24 types). Many of the masks known to carvers and found in the collection had not been carved in some years. Among these, distinguished by name, stylistic differentiation is minimal. Jean Vanden Bossche has suggested that this loss of stylistic articulation from mask to mask, already prevalent in the thirties in the western region, was due to acculturation, and he feared that within a number of years, Pende mask art would be dead, surviving only as routinized copy work of a former age. It is not possible to respond to this issue within the context of this paper, but we can note that overall artistic activity has not slackened. In addition to continuing use of some traditional mask types, the native and tourist market thrives on a whole new derivation of mask carving: miniatures of masked dancers (Fig. 6). At the same time, some carvers apparently seek to apply the creative potential inherent in the fragmented and flexible Western approach to the characterization of new social roles, e.g., the rebel. The Kauffman Museum collection should allow the means to further study this question of stylistic stereotyping and variability.

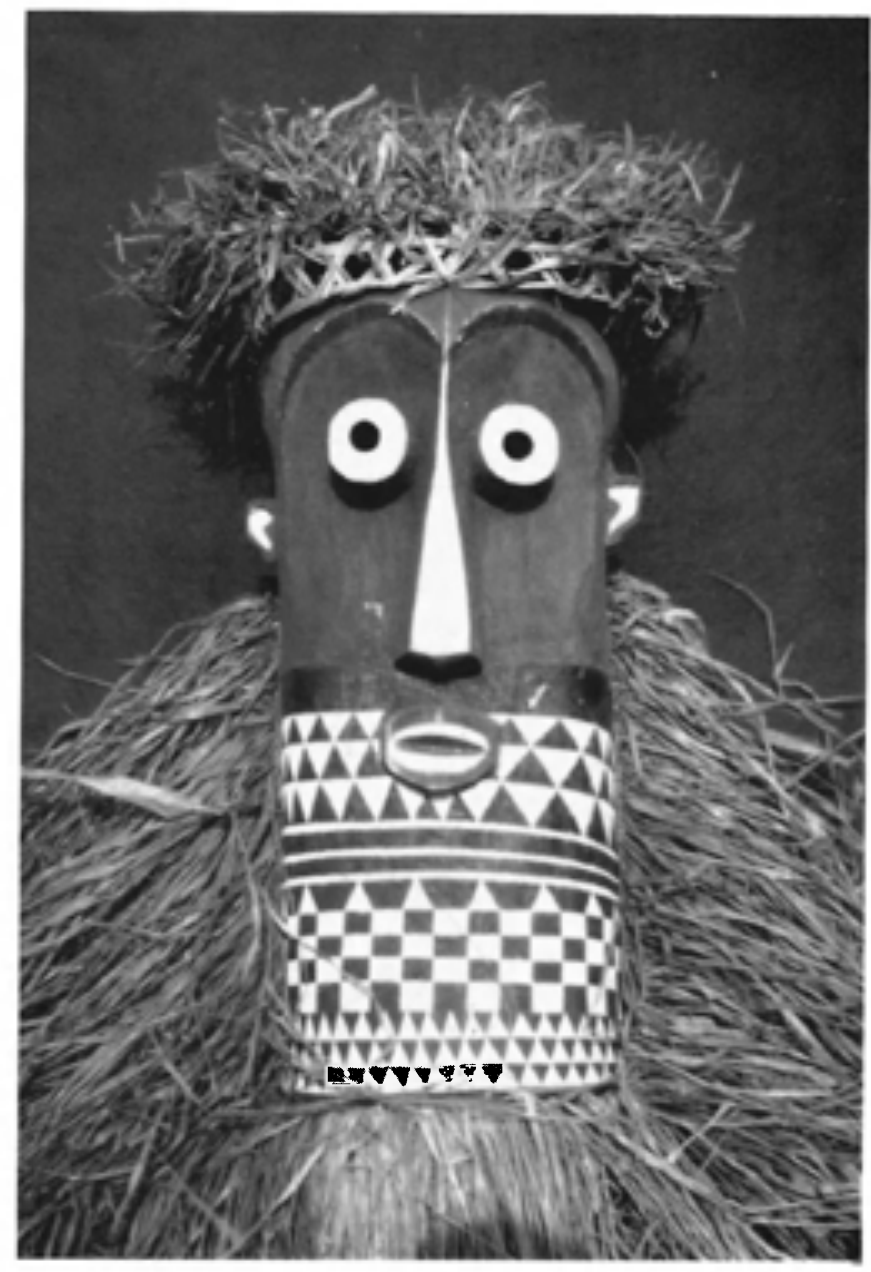

10. PHUMBU, THE KILLER, KASAI. CARVED BY KUOTSHAKano, CHIEF OF KUOTSHAKANO VILLAGE, AND DANCED IN CERTAIN CHIEFLY INAUGURATIONS.

since many of the mask types are present in two and three examples from different carvers.

All in all, the collection described here bears evidence of the vigorous continuation of Pende masking art in the present. The mechanisms for this continuity are characterized by inherent modes of life in each of the two areas represented. Continuity of carving in the Kasai region is assured so far by an adherence to a conserving, traditional world view, as individual masks are subsumed to religious and social categories arising from the social structure of chiefly orders, age grades and economic life. In the Bandundu region, however, a well-rooted tradition of fragmentation and particularization, as opposed to strong characterization, has been and is evident.

The National Museum of Zaïre in Kinshasa harbors a vast collection of masks from across the country which includes all the types alluded to here and many more. A growing awareness in Zaïre intellectual and artistic circles is concerned with authentic culture, of which the masks and their attendant ceremonies and dances are seen as a prime example. The continuing popular market demand for masks-for local ceremonial, entertainment, and decorative use, and for tourism-will stimulate competition among the artists; continued quality thus seems assured.

Kauffman Museum is an hour's drive north of Wichita ${ }^{-1}$ three hours west of Kansas City. The natives are very 